\title{
Implicações do estágio supervisionado na formação do professor de Ciências
}

\author{
Implicaciones de la etapa supervisada en la formación del profesor de \\ Ciencias
}

Implications of the stage supervised in the teaching of the Science teacher

Leda Goularte Machado ${ }^{1}$

Crisna Daniela Krause Bierhalz ${ }^{2}$

\begin{abstract}
Resumo
Das 3260 horas da Licenciatura em Ciências da Natureza, da UNIPAMPA - campus - Dom Pedrito, 420 são estágios curriculares (5 ao 9 semestre). Considerando o estágio um espaço de consolidação de habilidades construídas ao longo do curso, esta pesquisa participante traça o perfil do licenciando e visa compreender as relações entre o Estágio supervisionado e a formação docente. O embasamento teórico ultrapassa a concepção de formação como racionalidade técnica, sujeitos meros executores de decisões alheias e reafirma a perspectiva do desenvolvimento da consciência crítica, da colaboração e da transformação da qualidade social da escola. (PIMENTA, 2008). Os 22 licenciandos, matriculados em Estágio Supervisionado I, no ano de 2017, responderam um questionário (5 questões), do qual obteve-se os resultados: maioria do sexo feminino (17), com a idade entre 29 a 38 anos (11), provenientes do Ensino Médio Regular (08), seguido do curso normal(07). Os sentimentos que prevalecem são o medo (07) e a ansiedade (07), seguidos pela expectativa (03). 12 dos 22 estagiários afirmaram ser possível desenvolver um estágio interdisciplinar e 14 classificaram favoravelmente os conhecimentos teóricos adquiridos ao longo do curso, porém ressaltam a limitação de práticas e a insegurança perante a realidade escolar. Conclui-se que o estágio é um dos momentos de aproximação entre a Universidade e a Educação Básica e fundamental para relacionar teoria e prática no campo de atuação.
\end{abstract}

Palavras-Chave: Licenciatura; Estágio Supervisionado; Ciências da Natureza.

\section{Resumen}

De las 3260 horas de la Licenciatura en Ciencias de la Naturaleza, de la UNIPAMPA - campus - Don Pedrito, 420 son pasantías curriculares (5 a 9 semestre). Considerando la etapa un espacio de consolidación de habilidades construidas a lo largo del curso esta investigación participante traza el perfil del licenciante y pretende comprender las relaciones entre la Etapa supervisada y la formación docente. El fundamento teórico sobrepasa la concepción de la formación como racionalidad técnica, sujetos meros ejecutores de decisiones ajenas y reafirma la perspectiva del desarrollo de la conciencia crítica, de la colaboración y de la transformación de la calidad social de la escuela. (PIMENTA, 2008). Los 22 licenciantes, matriculados en la Etapa Supervisada I, en el año 2017, respondieron un cuestionario (5 preguntas), del cual se obtuvieron los resultados: mayoría del sexo femenino (17), con la edad entre 29 a 38 años (11), provenientes de la Enseñanza Media Regular (08), seguido del curso normal (07). Los sentimientos que prevalecen son el miedo (07) y la ansiedad (07), seguidos por la expectativa (03). 12 de los 22 pasantes afirmaron que es posible desarrollar una etapa interdisciplinaria y 14 clasificaron favorablemente los conocimientos teóricos adquiridos a lo largo del curso, pero resaltan la limitación de prácticas y la inseguridad ante la realidad escolar. Se concluye que la etapa es uno de los momentos de aproximación entre la Universidad y la Educación Básica y fundamental para relacionar teoría y práctica en el campo de actuación.

${ }^{1}$ Graduanda em Ciências da Natureza, Universidade Federal do Pampa; Dom Pedrito; Rio Grande do Sul; Brasil; ledagmachado@gmail.com

${ }^{2}$ Doutora em Educação, Pontífica Universidade Católica do RS (PUC-RS); Porto Alegre; Rio Grande do Sul; Brasil; crisnakrause@gmail.com 
Palabras clave: Licenciatura; Etapa Supervisada; Ciéncias de la naturaleza.

\begin{abstract}
Of the 3260 hours of the Undergraduate Degree in Natural Sciences, UNIPAMPA - campus - Dom Pedrito, 420 are curricular internships ( 5 to 9 semester). Considering the internship a space of consolidation of skills built along the course this participant research traces the profile of the licenciando and aims to understand the relations between the supervised Internship and the teacher training. Theoretical basis goes beyond the conception of training as a technical rationality, subjects mere executors of decisions of others and reaffirms the perspective of the development of critical awareness, collaboration and transformation of the social quality of the school. (PIMENTA, 2008). The 22 graduates, enrolled in Supervised Internship I, in 2017, answered a questionnaire (5 questions), from which the results were obtained: a majority of women (17), aged between 29 and 38 years (11), coming from the Regular High School (08), followed by the normal course (07). Feelings that prevail are fear (07) and anxiety (07), followed by expectation (03). 12 of the 22 trainees affirmed that it was possible to develop an interdisciplinary internship and 14 classified favorably the theoretical knowledge acquired during the course, but they emphasize the limitation of practices and the insecurity before the school reality. It is concluded that the internship is one of the moments of approximation between the University and the Basic Education and fundamental to relate theory and practice in the field of action.
\end{abstract}

Keywords: Bachelor's degree; Supervised internship; Science of Nature.

\title{
1. Contexto do trabalho e organização Do Estágio Supervisionado na Licenciatura em
}

\section{Ciências da Natureza}

A Universidade Federal do Pampa - UNIPAMPA surge da reivindicação da comunidade da região da Campanha do Rio Grande do Sul, mobilizada pelo movimento político de expansão das instituições federais de Ensino Superior, promovida pelo Governo Federal, no ano de 2008. Essa Universidade é organizada em uma estrutura multicampi, com um total de 10 (dez) campi, como se observa na figura 1. (FONSECA e BIERHALZ, 2016)

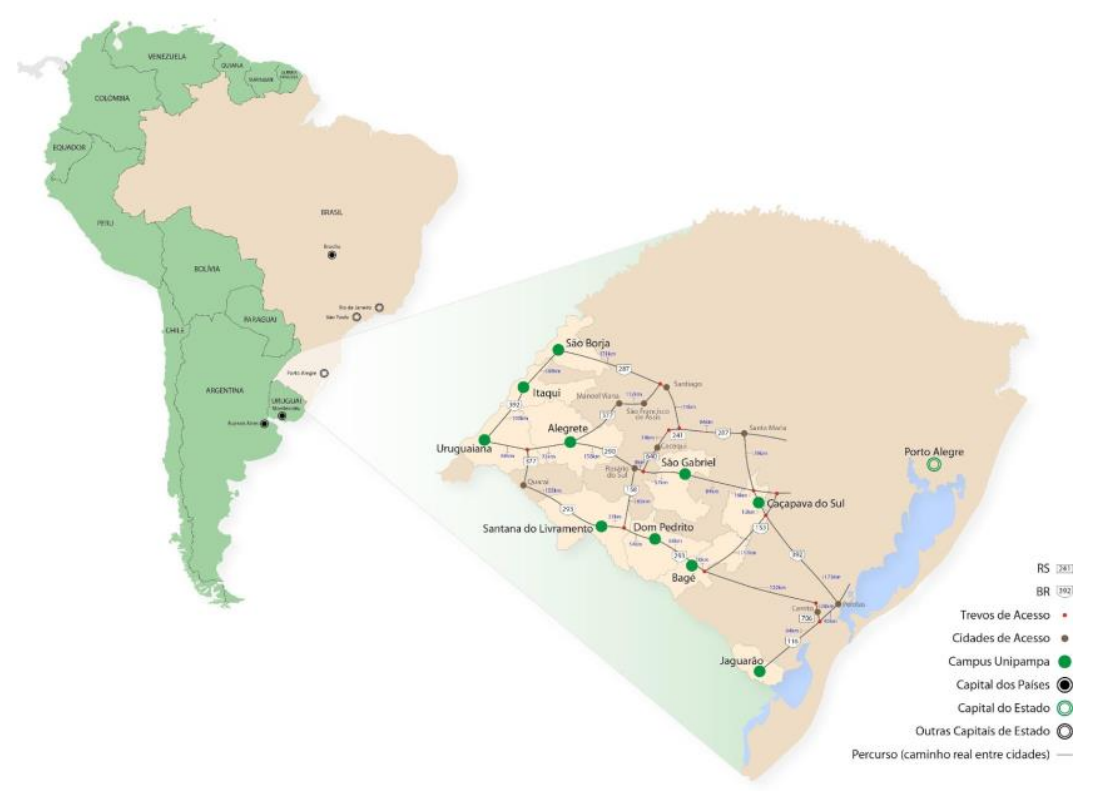

Figura 1 - Localização dos municípios que compõem a Unipampa 
Fonte:http://novoportal.unipampa.edu.br/novoportal/universidade, acesso em 6 de junho de 2016.

No campus Dom Pedrito funcionam cinco cursos de graduação: Bacharelado em Enologia, Zootecnia, Tecnologia em Agronegócio, Licenciatura em Educação do Campo e Licenciatura em Ciências da Natureza, sendo este o lócus da pesquisa.

De acordo com Bierhalz, Araújo e Lima (2013) o curso de Licenciatura em Ciências da Natureza propõe uma formação que habilita o licenciando a atuar no ensino de Ciências da Natureza tanto no Ensino Fundamental como no Ensino Médio, justificado pelo viés da interdisciplinaridade e pretende "estimular os alunos em sua curiosidade científica, incentivando-os à pesquisa e a reflexão ética perante a sociedade e a natureza, diante da perspectiva de aproveitamento das potencialidades locais para o desenvolvimento sustentável” (PPC, 2014, p. 18).

O curso está organizado em nove semestres, com 52 componentes curriculares obrigatórios, totalizando a carga horária de 2430 horas. Destes componentes quatro são estágios supervisionados, com foco nas três áreas basilares que constituem a área da Ciências da Natureza: Biologia, Física e Química, perfazendo o total de 420 horas, distribuídas da seguinte forma:

Tabela 1: Organização do estágio supervisionado no PPC 2013

\begin{tabular}{|c|c|c|c|}
\hline COMPONE & $\begin{array}{l}\quad \text { C } \\
\text { ARGA } \\
\text { HORÁRIA }\end{array}$ & $\begin{array}{r}\text { SE } \\
\text { MESTRE }\end{array}$ & EMENTA \\
\hline $\begin{array}{l}\text { Estágio } \\
\text { Supervisionado I: } \\
\text { Observação e vivência } \\
\text { do contexto escolar }\end{array}$ & 30 & 6 & $\begin{array}{l}\text { Observação da estrutura da rotina escolar, da construção } \\
\text { e viabilização do Projeto Político Pedagógico - PPP e do } \\
\text { regimento escolar. Contato com o professor do ensino de química, } \\
\text { física, biologia e ciências e a sala de aula. Análise e reflexão de } \\
\text { todas as observações e práticas pedagógicas em forma de relatório } \\
\text { final, considerando suas potencialidades e sistematizando o } \\
\text { processo que se efetivou }\end{array}$ \\
\hline $\begin{array}{l}\text { Estágio } \\
\text { Supervisionado II: } \\
\text { Observação e vivência } \\
\text { da sala de aula }\end{array}$ & 30 & 7 & $\begin{array}{l}\text { Planejamento e execução conjuntamente com os } \\
\text { professores da escola de uma proposta de ensino de ciências } \\
\text { interdisciplinar para a Educação Básica. Análise, reflexão e } \\
\text { avaliação da aula desenvolvida. }\end{array}$ \\
\hline $\begin{array}{c}\text { Estágio } \\
\text { Supervisionado III: }\end{array}$ & 18 & 8 & $\begin{array}{l}\text { Imersão no cotidiano escolar formal - Ensino Médio. } \\
\text { Elaboração e organização do projeto de estágio (planos de }\end{array}$ \\
\hline
\end{tabular}


RELACult - Revista Latino-Americana de Estudos em Cultura e Sociedade

\begin{tabular}{|c|c|c|c|}
\hline $\begin{array}{l}\text { Docência no Ensino } \\
\text { Fundamental }\end{array}$ & & & $\begin{array}{l}\text { unidade e aula) em Ciências, Química, Física e Biologia } \\
\text { considerando o diagnóstico e a efetiva articulação com a proposta } \\
\text { político-pedagógico da escola. Desenvolvimento e aplicação do } \\
\text { planejamento. Análise e reflexão dos resultados alcançados e as } \\
\text { experiências pedagógicas percebidas no decorrer do estágio em } \\
\text { forma de portfólio. }\end{array}$ \\
\hline $\begin{array}{l}\qquad \text { Estágio } \\
\text { Supervisionado IV: } \\
\text { Docência no Ensino } \\
\text { Médio }\end{array}$ & 18 & 9 & $\begin{array}{l}\text { Imersão no cotidiano escolar formal - Ensino Médio. } \\
\text { Elaboração e organização do projeto de estágio (planos de } \\
\text { unidade e aula) em Ciências, Química, Física e Biologia } \\
\text { considerando o diagnóstico e a efetiva articulação com a proposta } \\
\text { político-pedagógico da escola. Desenvolvimento e aplicação do } \\
\text { planejamento. Análise e reflexão dos resultados alcançados e as } \\
\text { experiências pedagógicas percebidas no decorrer do estágio em } \\
\text { forma de portfólio }\end{array}$ \\
\hline
\end{tabular}

Fonte: http://dspace.unipampa.edu.br/handle/riu/110

De acordo com o Projeto Pedagógico de Curso - PPC (2013, p.34), os componentes curriculares de estágio constituem-se espaços para a consolidação de habilidades e competências docentes que deverão ser construídas processualmente ao longo do curso. Cabe ressaltar que na licenciatura em questão, estes componentes concentram-se nos últimos semestres (tabela 1), corroborando o pensamento de Diniz Pereira (2007) ao afirmar que na realidade brasileira os estágios supervisionados em geral, aparecem bastante tardiamente no percurso formativo, alimentando a ideia de que chegou a hora de aplicar os conhecimentos aprendidos (ou supostamente aprendidos) por meio das disciplinas de conteúdo específico e/ou pedagógicos.

Mesmo que pesquisas e estudos no campo da formação de professores há várias décadas venham sinalizando a intrínseca relação entre teoria e prática, ainda se constata matrizes dissociativas em algumas Licenciaturas, talvez pela herança da racionalidade técnica, modelo fortemente instaurado na década de 70 , perspectiva tecnicista e epistemologicamente positivista, no qual o professor cumpre o papel de técnico e transmissor de conhecimentos (MONTEIRO, 2001).

No entanto cabe ultrapassar esta concepção, compreendendo que todas as atividades vinculadas à formação de professores devem ser/estar permeadas pela ação-reflexão-ação, entendida por Chaves Gamboa et al (2011, p. 143) como uma formação humana, que perpassa 
tanto o compromisso com a construção teórica, como pelas reflexões críticas. Estes autores reforçam que tanto a teoria construída, como as reflexões críticas devem ter como parâmetro epistemológico a relação com a prática e serem orientadas pela "filosofia da práxis".

No mesmo sentido Pimenta e Lima (2004, p.43) afirma que

o papel das teorias é iluminar e oferecer instrumentos e esquemas para análise e investigação que permitam questionar as práticas institucionalizadas e as ações dos sujeitos e, ao mesmo tempo, colocar elas próprias em questionamento, uma vez que as teorias são explicações sempre provisórias da realidade.

Considerando o Estágio Supervisionado como a primeira porta de entrada para profissão, sendo este o espaço no qual o professor em formação vislumbra a prática profissional pelo contato com a realidade educacional e suas múltiplas facetas (Lombardi, 2007), bem como um campo de conhecimento produzido nas interações com a realidade social (Pimenta e Lima, 2004), pretende-se neste texto apresentar e discutir algumas reflexões vividas no Curso de Licenciatura em Ciências da Natureza, que perpassam pelo perfil do licenciando em Ciências da Natureza, bem como por suas compreensões sobre o estágio supervisionado e formação docente.

\section{Caminhos metodológicos}

Metodologicamente, com base nos procedimentos técnicos, essa pesquisa caracterizou-se como uma pesquisa participante, pois houve "[...] interação entre os pesquisadores e os membros da situação investigada" (GIL, 2002, p. 55). Os sujeitos foram os acadêmicos da Licenciatura em Ciências da Natureza que participaram da Componente Curricular "Estágio Supervisionado I", ministrada no primeiro semestre do ano de 2017.

Classificou-se a abordagem como qualitativa (GIL, 2002), pois, considerou-se a percepção dos sujeitos sobre o estágio supervisionado, preocupando-se, não apenas em contabilizar os resultados, mas também em entendê-los e discuti-los.

Como instrumento foi aplicado aos 22 sujeitos, um questionário físico, com questões relacionadas ao perfil e cinco questões sobre as concepções de estágio.

Para análise dos resultados, foi utilizado a "Análise de Conteúdo" proposta por Bardin (1977), estruturada em três etapas distintas: (1) pré-análise, (2) exploração do material e (3) tratamento dos resultados.

Na pré-análise organizou-se o material a ser analisado com o intuito de torná-lo operacional. Na exploração do material codificaram-se os questionários com caracteres 
alfanuméricos L-01, L-02, L-03,... L-22, respectivamente, sendo a letra "L" relacionada à palavra licenciando e o numeral uma maneira de identificação para substituir o nome.

As respostas de cada atividade foram transcritas fielmente e sintetizadas em trechos, frases e palavras, até emergirem três categorias-chave: I) Perfil dos sujeitos da pesquisa; II) Sentimentos referentes ao estágio e III) Concepções relacionadas ao estágio supervisionado. A discussão dos resultados é apresentada a seguir:

\section{Perfil, sentimentos e Concepções de Estágio Supervisionado}

A pesquisa foi realizada com 22 alunos do curso da Licenciatura em Ciências da Natureza, no primeiro semestre de 2017, com idades entre 20 e 60 anos. Tendo representatividade de 17 mulheres (77\%) e 5 homens (23\%).

Através do comparativo entre a idade e gênero dos pesquisados, percebe-se que dos 22 licenciandos, (6 mulheres e 2 homens) têm de 20 a 30 anos; (6 mulheres e 2 homens) têm de 31 a 40 anos; ( 3 mulheres e 2 homens) têm de 41 a 50 anos e 1 têm mais de 51 anos. Tais informações demarcam um perfil feminino com idades heterogêneas na LCN.

A prevalência de mulheres na turma da Licenciatura em Ciências da natureza, complementa os dados de outras pesquisas que buscam compreender o perfil e a identidade das Licenciaturas, uma delas é a de Rêses (2008, p.32) para quem há "profissões historicamente destinadas ao 'gênero' feminino, entre elas a de professor'.

Quanto ao aspecto profissional, cinco licenciandos já atuam como professores na Educação Básica, quatro são funcionários públicos e seis atuam no comércio local. Constatase que dos 22 sujeitos da pesquisa, 15 caracterizam-se com dupla jornada, aliando o trabalho com os estudos a nível superior no noturno.

Em relação à formação a nível médio, percebe-se também uma heterogeneidade: Ensino Médio Regular (08), curso normal (07), ensino técnico (02), Educação de Jovens e Adultos - EJA (03), Exame Nacional de Ensino Médio - ENEM e supletivo (01).

Após identificarmos o perfil dos investigados, categorizamos o que eles sentem e pensam em relação ao estágio supervisionado, salientando que esta pesquisa foi desenvolvida na primeira aula de Estágio Supervisionado I.

A primeira questão investigou os conhecimentos dos licenciandos a respeito da organização do estágio supervisionado no curso da LCN e obteve-se como resposta que 18 dos 22 estagiários não conheciam a organização. Apenas quatro responderam que sim. Este dado deve ser utilizado como indicador, para que tanto o Núcleo Docente Estruturante, como 
a Comissão de Curso elaborem estratégias formativas que contemplem discussões sobre o estágio supervisionado. São algumas possibilidades: palestras, mesas redondas, mini cursos sobre a organização e o funcionamento dos estágios na Licenciatura, nos quais poderão participar tanto professores coordenadores, supervisores, estagiários, equipe gestora e alunos da educação básica. Este resultado reforça o supracitado por Diniz Pereira (2007) ao afirmar que existe um distanciamento entre as demais disciplinas do currículo formativo e os estágios supervisionados, sinalizando a necessidade de enfrentamento.

A segunda questão procurou saber se na opinião dos licenciandos é possível desenvolver um estágio interdisciplinar, considerando que o curso tem esta abordagem como base e o próprio estágio II (tabela 1) indica em sua ementa a elaboração, execução e avaliação de uma proposta interdisciplinar. Obteve-se como resposta: 15 (Sim), 3 (Não) e 4 (Talvez).

A interdisciplinaridade está presente nos cursos de formação de professores, seja através de concepções que embasam a construção dos projetos pedagógicos, de práticas pedagógicas desenvolvidas nos diferentes componentes curriculares ou pela participação em programas de formação docente como o Programa Institucional de Bolsas de Iniciação a Docência (Pibid), residência pedagógica entre outros que apresentam entre seus objetivos o desenvolvimento de ações interdisciplinares. Trata-se de um reflexo dos desafios atuais presentes na sociedade contemporânea que exigem discussões que ultrapassem a forma fragmentada de analisar as situações.

A resposta desta questão revela que mesmo com todas as dificuldades na perspectiva da interdisciplinaridade, (JAPIASSÚ, 1976; FAZENDA, 2012, MORIN, 2016), o posicionamento dos futuros professores corrobora a relevância do olhar amplo para as abordagens do ensino, que passam a preocupar-se cada vez mais com a compreensão e totalidade do conhecimento do que com a memorização e fragmentação.

A terceira questão solicitou que cada licenciando descrevesse o estágio com um sentimento (gráfico 1): 


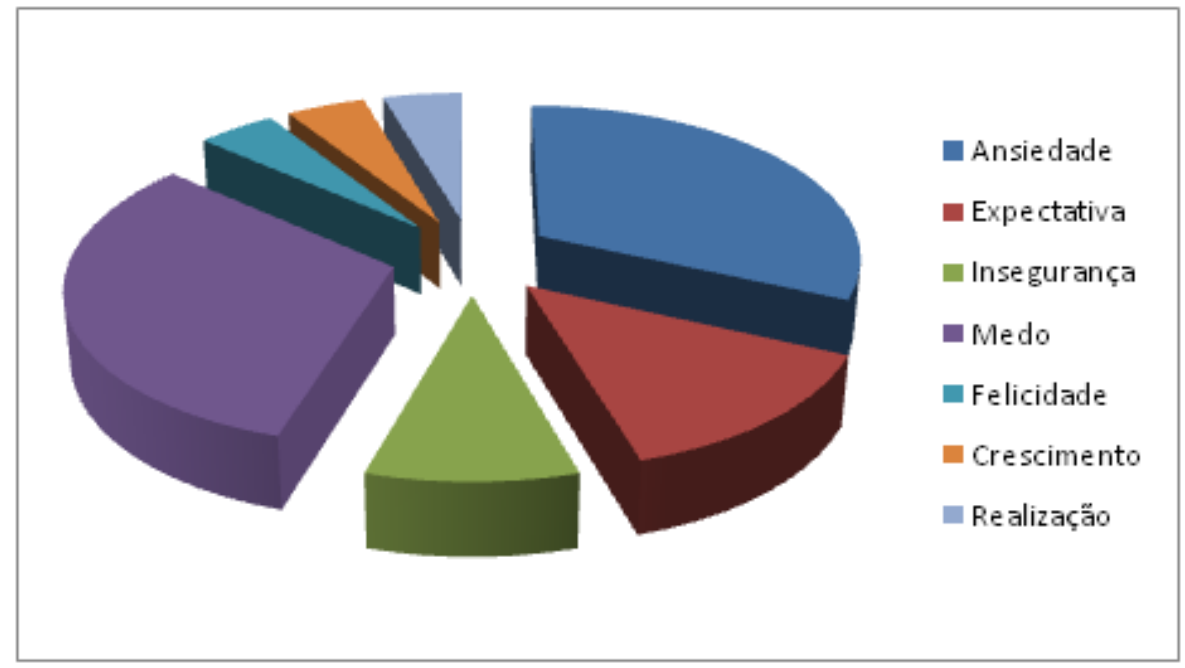

Gráfico 1 - Representação dos sentimentos acerca do Estágio Supervisionado.

Fonte: Autores (2018)

Constata-se que os dois sentimentos mais expressivos são a ansiedade (07) e o medo (07). Talvez possa ser explicado pelo fato dos licenciandos considerarem esta situação "nova", "desconhecida". Salienta-se que por mais que o estagiário tenha contato com a escola, com a realidade escolar, este contato foi como aluno, e ao se deparar com a situação na qual é responsável pelo conteúdo, pela turma, pela aprendizagem, caracteriza-se diferente e complexa. A sensação de despreparo é muito forte e por vezes interfere negativamente, como relata L21 "Acredito que nos conhecimentos em si, não há falhas, e sim no nosso aprendizado desses conhecimentos, pois podemos até ter aprendido, mas vamos conseguir passar ao aluno?". Um fator que pode minimizar este sentimento é a presença do professor regente da turma (supervisor do estagiário) acompanhando e orientando o estagiário.

Ao serem solicitados para descrever o estágio com uma concepção observa-se através do gráfico 2, que prevalece a experiência (05), seguidos da prática, descoberta e aprendizado, ambos com três respostas. 


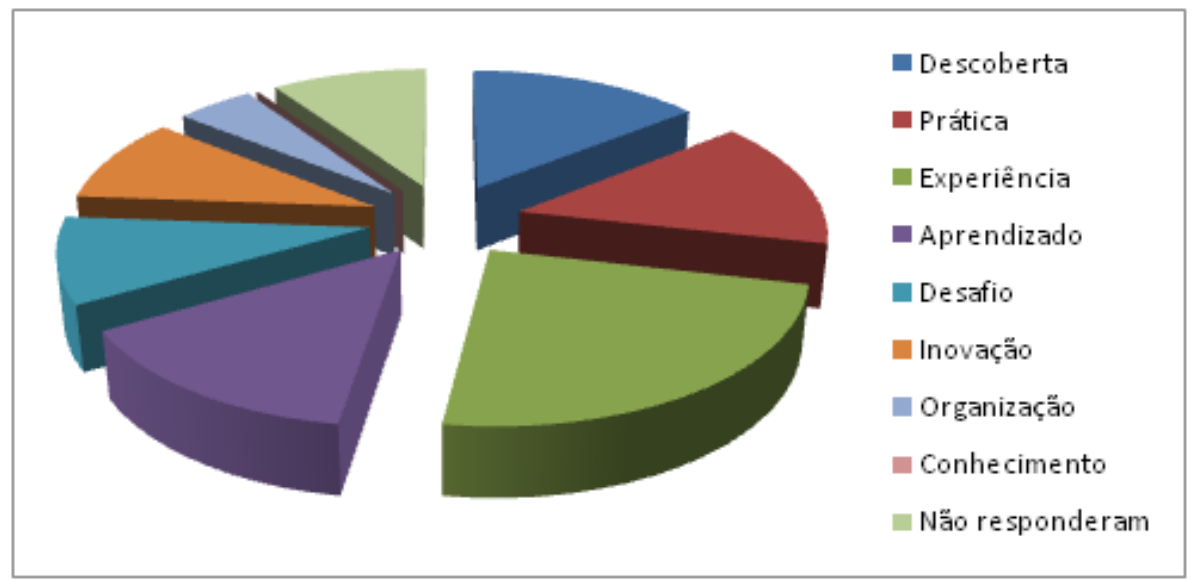

Gráfico 2 - Representação das concepções acerca do Estágio Supervisionado.

Fonte: Autores (2018)

O fato de boa parte dos estagiários afirmarem que a concepção que prevalece no estágio é a experiência, é corroborado pelos estudos de Castoldi e Polinarski (2009), ao afirmarem que o estágio tem exatamente o papel de proporcionar para os licenciandos o primeiro contato com as situações vivenciadas em sala de aula como professor, ressaltam que essa experiência não propicia, nem poderia propiciar, a vivência de todas as situações presentes no exercício da função docente, mas torna-se um espaço significativo. Lima (2001) corrobora com a ideia supracitada ao afirmar que o estágio é, sob alguns aspectos incompleto, pois embora se constitua como um importante espaço de aprendizagem da profissão docente e de construção profissional é no efetivo exercício do magistério que a profissão docente vai ser de fato aprendida, através da pesquisa e reflexão na e sobre a própria prática.

A quarta questão investigou a avaliação dos licenciandos em relação aos conhecimentos teóricos desenvolvidos ao longo do curso e sua utilização no estágio supervisionado, para tabulação das respostas utilizou-se cinco categorias apresentadas no gráfico 03.

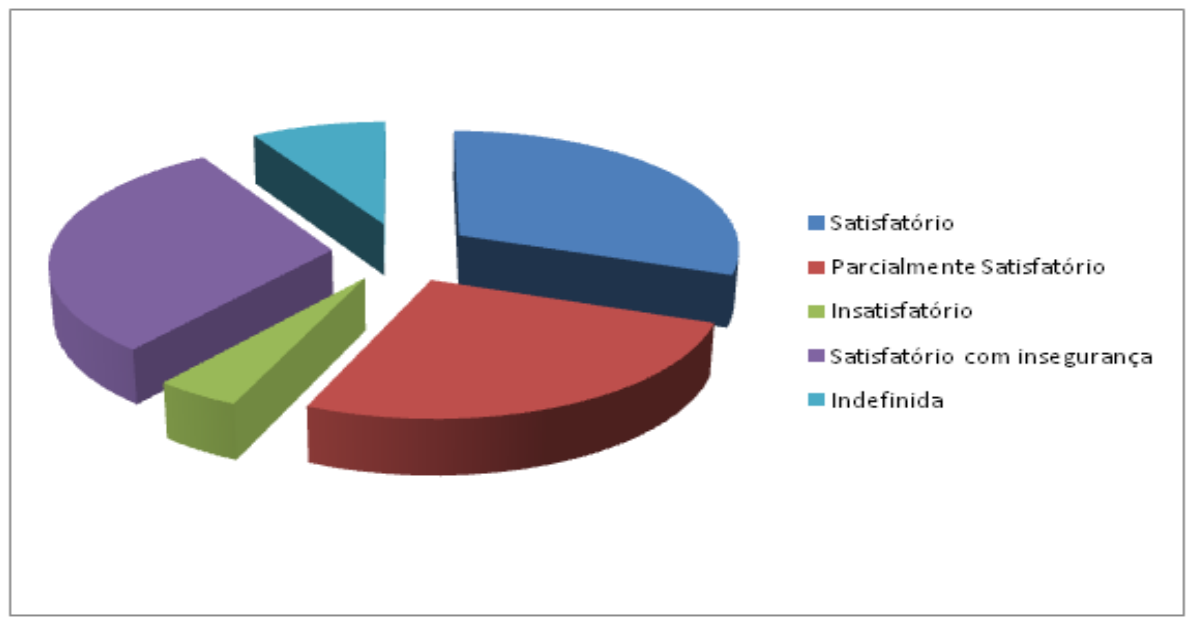


Gráfico 3 - Representação da avaliação teórica conceitual acerca do Estágio Supervisionado.

Fonte: Autores (2018)

Ao avaliarmos o total de respostas, percebe-se que 14 dos 22 acadêmicos avaliaram a base conceitual teórica como satisfatória, porém entre as respostas cabe frisar que metade não expressou o sentimento de insegurança em relação a esta base, e outra metade demonstrou insegurança expressa por: "não sinto-me preparada”, "a única falha é termos de juntar os conhecimentos sozinhos", "me sinto muito insegura em relação à prática mesmo" e " é dificil assimilar todo o conteúdo, terei que buscar, estudar mais”.

A resposta satisfatória é exemplificada pelo L7 ao afirmar que "os conhecimentos são extremamente importantes, talvez não entre muito a fundo, mas sua base é muito forte, nos deixando tranqüilos para pelo menos vencer o estágio". Em contrapartida L10 ressaltou sua visão satisfatória mas com insegurança ao expressar: " $O$ curso oferece os conhecimentos teóricos necessários, mas não sinto-me preparada para encarar uma sala de aula."

Seis acadêmicos avaliam os conhecimentos como parcialmente satisfatórios, identificando principalmente a necessidade de retomar conteúdos, pesquisar, descrito nos trechos: "Considero bons, mas o estagiário deverá pesquisar e estudar mais" (L17). "Creio que todas as disciplinas precisam ser estudadas e muito, antes de aplicá-las"(L21).

A análise das respostas demonstra uma grande preocupação com a transposição didática, elemento que busca diminuir a distância entre o saber científico e o saber ensinado, definida por Chevallard (1991, p.45) como

\footnotetext{
Um conteúdo de saber que foi designado como saber a ensinar, sofre a partir de então um conjunto de transformações adaptativas que vão torna-lo apto para ocupar um lugar entre os objetos de ensino. $\mathrm{O}$ "trabalho" que transforma um objeto de saber a ensinar em um objeto de ensino é denominado Transposição Didática.
}

No mesmo sentido dos estudos de Chevallard (1991), Alarcão (1996) explicita que um dos maiores problemas dos cursos de formação inicial é a falta de articulação entre as disciplinas, bem como a falta de articulação entre o conteúdo ensinado e a prática efetiva, cabendo ao professor em formação fazer a "ponte" entre teoria e prática. Muitos licenciandos criam a expectativa que os estágios supervisionados são as disciplina integradoras.

As repostas obtidas a partir do questionamento relacionado aos maiores desafios em relação ao estágio supervisionado, são apresentadas no gráfico 4. 


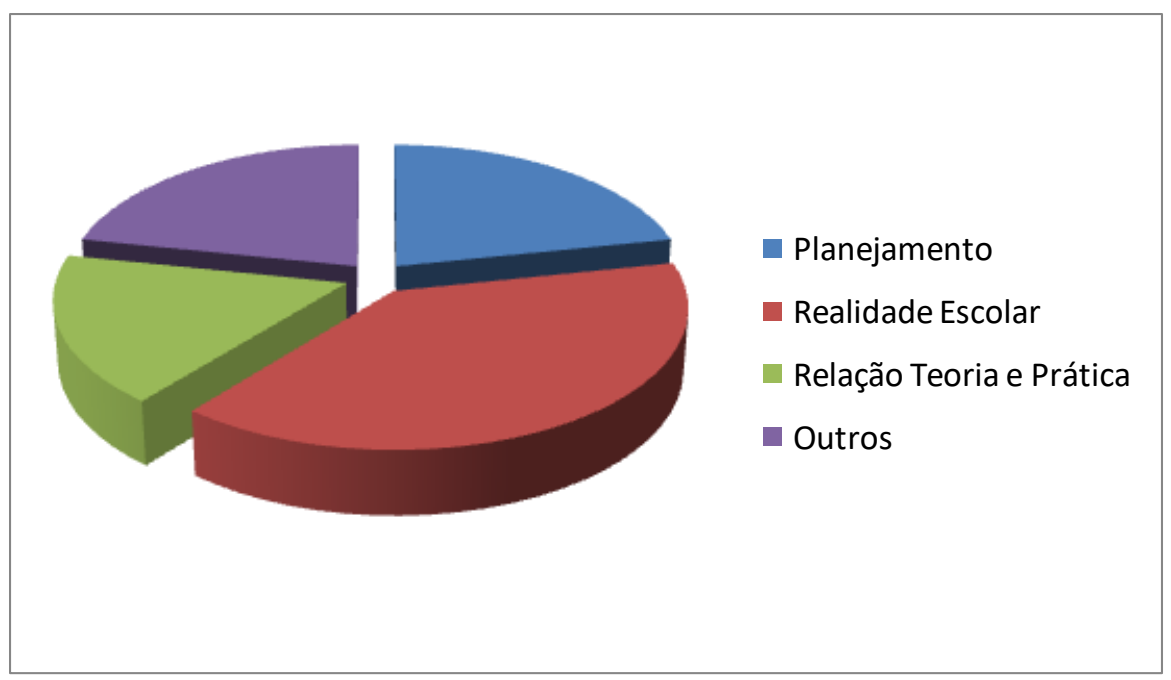

Gráfico 4 - Representação dos desafios acerca do Estágio Supervisionado.

Fonte: Autores (2018)

Cinco acadêmicos mencionaram que o maior desafio relaciona-se ao planejamento, novamente relacionado a insegurança de utilizar o modelo adequado, ou cumprir com as expectativas do professor regente e do coordenador de estágio. Explicitados por L13: “não temos conhecimento de como elaborar uma avaliação (prova)" e por L14 "como, elaborar e avaliar um trabalho, ou então elaborar um plano de aula, acho um pouco falho esses aspecto".

Em relação à realidade escolar, mencionada em nove respostas, destaca-se a grande preocupação em saber como tratar casos de indisciplina, exemplificado no depoimento de L17 "não saberia lidar com a indisciplina dos alunos em sala de aula". Percebe-se nas respostas uma preocupação com o distanciamento entre o que é ensinado na universidade e o que os alunos terão que desenvolver na Educação Básica, expressa por L19 “a realidade na escola é totalmente diferente onde nos deparamos com as dificuldades e inúmeras adversidades".

Para Pimenta e Lima (2004, p.10) a perspectiva técnica no estágio gera um distanciamento da vida e do trabalho concreto que ocorre nas escolas, uma vez que as disciplinas que compõem os cursos de formação não estabelecem os nexos entre os conteúdos, geralmente compreendidos como teorias com o que desenvolvem e a realidade nas quais o ensino ocorre.

Todos elementos discutidos ao longo do texto reforçam a necessidade da superação do distanciamento entre teoria e prática que contribui com o empobrecimento do estágio supervisionado. Todas as disciplinas do curso de Licenciatura tem como finalidade formar professores, a partir da análise, da crítica e da proposição de novas maneiras de fazer educação. Esta postura frente à formação vai evidenciar a necessidade de explicitar todos os 
componentes curriculares da matriz formativa como teoria e prática (e não teoria ou prática). (Pimenta e Lima, 2004).

Nesse sentido as autoras Pimenta e Lima (2004) defendem uma nova postura, uma redefinição do estágio que deve caminhar para a reflexão, a partir da realidade educacional, aproximando Universidade e Educação Básica.

Esta aproximação é evidenciada em duas respostas, nas quais os licenciandos identificam o PIBID como uma possibilidade e reconhecem o seu potencial. L14 expressa: "Hoje sou pibidiano e aprendi a amar a docência na bolsa, que nos insere no ambiente escolar, no contexto da escola, em um contato direto com os educandos, essa é uma experiência única que serve como um pré estágio"; "Como não participei de nenhuma prática em sala de aula, como por exemplo, as práticas que o PIBID oferece, acho tudo muito incerto".

\section{Considerações}

Cabe ressaltar que assim como Alarcão (1996) consideramos a formação inicial um período de formação privilegiado, na medida em que se torna possível desenvolver os conhecimentos teóricos e práticos, não só no sentido de reprodução, mas também no sentido crítico de escolher caminhos próprios que os encaminham para uma docência reflexiva, respeitando as características e diferenças de cada contexto.

A partir deste conceito procuramos discutir as concepções de um grupo de futuros professores de Ciências da Natureza a respeito do estágio supervisionado, pensando e repensando sobre as possibilidades formativas vividas durante o curso e que de certa forma culminam em uma decisão de continuar ou não na docência. A experiência única geralmente vivida no estágio é traduzida pelo licenciando como o momento em que se enxerga professor, testa seus modelos, diariamente avança e recua em suas percepções, se identifica ou não com a sala de aula e todas as situações nela encontradas.

Torna-se importante momentos ao longo do curso que possibilitem a reflexão sobre o papel do estágio supervisionado na formação do professor, momento ímpar para pensar e repensar sobre suas práticas, no que fazer com seus alunos, que conteúdos escolher, fazendo uma reflexão do que seria mais adequado para cada momento (IMBERNÓN, 2001).

\section{Referências}

ALARCÃO, I. Formação reflexiva de professores: estratégias de supervisão. Porto: Porto Editora, 1996. 
BIERHALZ, C. D. K.; ARAUJO, R. R. de; LIMA, V. de A. Licenciatura Interdisciplinar em Ciências da Natureza: Análise do Projeto Pedagógico de Curso. In: Anais. SIIEPE - Simpósio Internacional sobre Interdisciplinaridade no Ensino,na Pesquisa e na Extensão - Região Sul. Universidade Federal de Santa Catarina, 2013. Disponível em: https://pt.scribd.com/document/209883374/Bierhalz-et-al-Licenciatura-Interdisciplinar-emCiencias-da-Natureza , acesso em 18 Jul. 2017.

BARDIN, L. Análise de Conteúdo. Lisboa, Portugal; Edições 70, LDA, 2009.

CASTOLDI, R.; POLINARSKI, C.A. Considerações sobre estágio supervisionado por alunos licenciandos em Ciências Biológicas. In: VII Encontro Nacional de Pesquisa em Educação em Ciências, Florianópolis, 2009. Anais do VII ENPEC, Belo Horizonte: ABRAPEC, 2009.

CHAVES-GAMBOA, M.; GAMBOA, S. S.; TAFFAREL, C. Prática de ensino: formação e emancipação. 3 ed., Macéio: EDUFAL, 2011.

CHEVALLARD, Y. La tranposición didáctica: Del saber sabio al saber enseñado. Traduzida por Claudia Gilman. Editora Aique: Buenos Aires. 1991.

DINIZ PEREIRA, J. E. Formação de professores, trabalho docente e suas repercussões na escola e na sala de aula. Educação \& Linguagem, São Paulo: Universidade Metodista de São Paulo, ano 10, n. 15, p. 82-98, jan./jun. 2007.

FAZENDA, I. C. A. Interdisciplinaridades: história, teoria e pesquisa. Campinas: Papirus, 2012.

FONSECA, E. M.; BIERHALZ, C. D. K. Discutindo articulações entre ensino de Ciências e Educação do Campo através da análise dos cadernos. Revista Brasileira de Educação do Campo, Tocantinópolis, v. 1, n. 2, p. 255-278, 2016.

GIL, A. C. Como elaborar projetos de pesquisa. 4 ed. São Paulo: Atlas, 2002.

IMBERNON, F. Formação docente e profissional - formar-se para a mudança e a incerteza. São Paulo: Cortez, 2001.

JAPIASSU, H. Interdisciplinaridade e patologia do saber. Rio de Janeiro: Imago, 1976.

LIMA, M. S. L. A formação contínua dos professores nos caminhos e descaminhos do desenvolvimento profissional. Doutorado em Educação. Faculdade de Educação da Universidade de São Paulo (FEUSP), 2001.

LOMBARDI, R. F. Estagio Supervisionado: importante na e para a formação do professor. In: CARVALHO, G. T. R. D. de; UTUARI, S.. (Org.). Formação de professores e estágios supervisionados: algumas veredas. São Paulo: Andross, 2007.

MONTEIRO, A. M. F. da C. Professores: entre saberes e práticas. In: Educação \& Sociedade. ano XXII. n. 74. Abril/2001. Disponível em: http://www.scielo.br/pdf/es/v22n74/a08v2274

MORIN, E. O método 1: a natureza da natureza. Porto Alegre: Editora Sulina, 2016.

PIMENTA, S. G. O Estágio na Formação de Professores: unidade teoria e prática. São Paulo: Cortez, 2005.

PIMENTA, S. G.; LIMA, M. S. L. Estágio e Docência. Coleção docência em formação. Séries saberes pedagógicos. São Paulo: Cortez, 2004. 
PIMENTA, S. G.; GHEDIM, E. Professor Reflexivo no Brasil: gênese e crítica de um conceito. São Paulo: Cortez, 2008.

RÊSES, E. da S.. De vocação para profissão: organização sindical docente e identidade social do professor. 2008. 308 f. Tese de Doutorado, Departamento de Sociologia, Universidade de Brasília, Brasília.

UNIVERSIDADE FEDERAL DO PAMPA. Campus Dom Pedrito. Projeto Político Pedagógico (PPC) do Curso de Licenciatura em Ciências da Natureza. Disponível em: http://dspace.unipampa.edu.br/bitstream/riu/110/3/PPC_Ci\%C3\%AAnciasdaNatureza_DomP edrito_2015.pdf Acesso em, em 10 Set 2016. 